\title{
Analysation of the Effect of the Contact Properties on Soil's Penetration Resistance in Discrete Element Simulations
}

\author{
K. Kotrocz ${ }^{1}$, Gy. Kerényi ${ }^{1}$ \\ ${ }^{1}$ Budapest University of Technology and Economics, Department of Machine \\ and Product Design \\ Müegyetem rkp. 3-9., 1111 Budapest, Hungary \\ e-mail: kotrocz.krisztian@gt3.bme.hu
}

Abstract: Cone penetration in-situ tests are commonly used to measure the cone index of the soils. This measurement process can be modelled very well with Discrete Element Method (DEM) if the parameters of the correct contact model are defined properly. In this paper the Hertz-Mindlin with bonding contact model are used and the effect of the properties of this contact model on soil's penetration resistance is investigated. Our aim was to determine those contact parameters which play important role in the penetration process, thus are necessary to take into account while calibrating the discrete element soil model to the results of real penetration tests.

Keywords: DEM; soil; penetration resistance; cone penetrometer

\section{Introduction}

Soil compaction is one of the most known problem in agriculture, and it has negative effect on crop growth and yield. In the last few decades, the size of the agricultural machines has been increased which resulted in increasing the mass of the machines, thus increasing the vertical load applied into the soil during tillage operations as well. This normal stress is generated in the soil by the driven and nondriven wheels, and is responsible for soil compaction.

One of the most common method to measure soil strength is by cone penetrometers [1]. During the measurement, the penetrometer cone is pressed into the soil up to given depth, while the vertical force acting on the tip of the cone is 
measured. By dividing this force with the projected area of the cone, the soil's resistance to penetration can be determined [2].

Thanks to the development of the information technology in the last few decades, researchers can simulate mechanical processes using numerical methods. One of these is the Finite Element Method (FEM) which can be used to model continuous materials by approximating the geometry with the finite element mesh [3], and calculating the displacement of the nodes. This method is very useful in multi mass simulations (e. g. in modelling the vibration of a one-cylinder engine crankshaft) [4] or performing static analysis on continuous materials as well [5]. It is also used for simulation of the penetration process [6], but because of soil consists of individual particles, these calculations can be used only to determine the location of the hard layers in the soils [7] and are not able for proper simulation of the soil's deformation. More suitable method seems to be the Discrete Element Method (DEM) which is established by Cundall and Strack [8] and is used to model bulk materials such as soils. Tanaka et al created a two-dimensional (2D) discrete element model for modelling of the penetration in-situ test [9], however Butlanska et al investigated this phenomenon in three dimension (3D) [10]. They concluded that the results highly depend on whether full, half or quarter circle soil geometries are used, and the use of spherical elements with non-cohesive or non-bonded contact models results in large error [11].

In our work, we used spherical elements with the Hertz-Mindlin with bonding contact model to simulate the penetration process in cohesive soils. Our aim was to investigate the effect of the contact properties on simulation results, namely on the penetration resistance-penetration depth curve. The results of the paper can be used further when calibrating the contact properties to the results of in-situ penetration tests.

\section{Materials and Methods}

\subsection{Discrete element contact models}

DEM is based on dividing the process into small timesteps of $\Delta t$, and calculating the displacement vectors of the individual elements according to Newton's $2^{\text {nd }}$ law in each timestep. In most cases, the particles are non-deformable during the simulations, thus the importance of the contact models between the elements are very high. In our calculations, we used the Hertz-Mindlin with bonding model available in EDEM 2.7 software and shown in Fig. 1, which consists two separate model, the Hertz-Mindlin model (Fig. 1/a) and the Parallel Bond contact model (Fig. 1/b). 


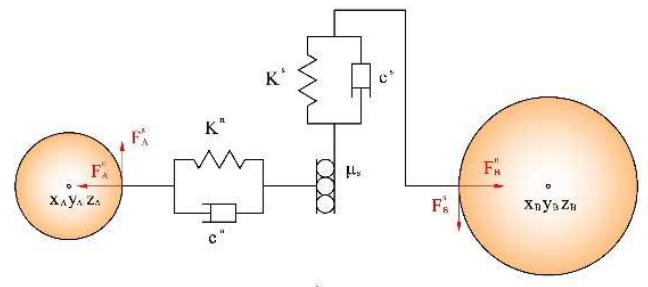

a)

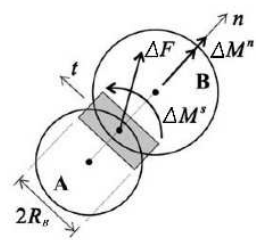

b)

Figure 1. The Hertz-Mindlin (a) and the Parallel Bond contact models (b) [15].

With the first, the friction between the elements can be simulated, and with Parallel Bonds, the cohesion between soil particles can be taken into account. In the HertzMindlin contact model $[12,13,14]$, the contact force transferred from one particle to another, is divided into normal $\left(F^{n}\right)$ and shear force $\left(F^{s}\right)$. The normal component can be determined using Eq. 1:

$$
F^{n}=\frac{4}{3} \cdot E^{*} \cdot \sqrt{R^{*}} \cdot\left(U^{n}\right)^{\frac{3}{2}},
$$

The $E^{*}$ represents the equivalent elastic modulus, $R^{*}$ is the equivalent radius and $U^{n}$ is the normal overlap of the contacting elements. These can be determined from the parameters, $E, R$ and the location of the particles. The contact shear force $\left(F^{s}\right)$ can be calculated from the equivalent shear modulus $\left(G^{*}\right)$ and tangential displacement $\left(U^{s}\right)$ according to Eq. 2:

$$
F^{s}=-\left(8 \cdot G^{*} \cdot \sqrt{R^{*} \cdot U^{n}}\right) \cdot U^{s},
$$

In addition, it has a limit according to Coulomb's law of friction, namely it cannot be higher than the value from Eq. 3:

$$
F^{s} \leq F^{n} \cdot \mu_{s}
$$

In Eq. 3 , the $\mu_{s}$ denotes to the friction coefficient between the soil particles. In addition, there are damping forces to model the energy dissipation of the particle's collisions, they can be divided into normal $\left(F^{n} d\right)$ and shear components $\left(F^{\mathrm{s}} d\right)$ as well and can be calculated as:

$$
\begin{aligned}
& F_{d}^{n}=-2 \cdot \sqrt{\frac{5}{6}} \cdot \beta \cdot \sqrt{K^{n} \cdot m^{*}} \cdot v^{n}{ }_{r e l}, \\
& F_{d}^{s}=-2 \cdot \sqrt{\frac{5}{6}} \cdot \beta \cdot \sqrt{K^{s} \cdot m^{*}} \cdot v_{r e l}^{s} .
\end{aligned}
$$


In Eq. 4 and Eq. 5, $K^{n}, K^{s}, m^{*}, v_{r e l}^{n}$ and $v_{r e l}^{s}$ are the normal and shear contact stiffness (Fig. 1/a), the equivalent mass and the normal and shear component of the relative velocity $\left(v_{r e l}\right)$ of the contacting elements, respectively. In addition, $\beta$ can be calculated with Eq. 6 using the coefficient of restitution $(e)$.

$$
\beta=\frac{\ln e}{\sqrt{\ln ^{2} e+\pi^{2}}} .
$$

Parallel Bonds can be added to the model at the time of $t_{\text {Bond }}$ to represents the cementinous effect between the elements. This contact model can be envisioned as a set of elastic springs around the contact point with bond radius of $R_{B}$ [15]. The bonds act parallel with the Hertz-Mindlin contact model, therefore additional normal $\left(\Delta F^{n}\right)$ and shear forces $\left(\Delta F^{s}\right)$ are summed to the corresponding components:

$$
\begin{gathered}
\Delta F^{n}=-k_{B}^{n} \cdot A_{B} \cdot \Delta U^{n}, \\
\Delta F^{s}=-k_{B}^{s} \cdot A_{B} \cdot \Delta U^{s} .
\end{gathered}
$$

In Eq. 7 and Eq. $8, k_{B}^{n}, k_{B}^{s}, A_{B}$ and $\Delta U^{n}$ and $\Delta U^{s}$ are the bond's normal and tangential stiffness, the area of the bond and the normal and shear component of the relative displacement of the contacting elements, respectively. These displacements are incremental, thus are calculated from the time of $t_{\text {Bond }}$, when both of them are set to zero. Because Parallel Bond behaves as beam contact between the particles, it can transmit moments through the elements in both normal and tangential direction as well. These moments can be calculated similar to the bond forces, but the area of the bond should be changed to the polar moment of inertia $\left(J_{B}\right)$ and the relative displacements to the relative rotations of the elements $\left(\Delta \theta^{n}\right.$ and $\left.\Delta \theta^{s}\right)$, as it is shown in Eq. 9 and Eq. 10.

$$
\begin{aligned}
& \Delta M^{n}=-k_{B}^{n} \cdot J_{B} \cdot \Delta \theta^{n}, \\
& \Delta M^{s}=-k_{B}^{s} \cdot \frac{J_{B}}{2} \cdot \Delta \theta^{s} .
\end{aligned}
$$

Similar to the relative displacements of $\Delta U^{n}$ and $\Delta U^{s}$, the relative rotations are set to zero at the bond's formation time of $t_{B o n d}$ as well. In addition, there are limit stresses (i. e. the normal and tangential Parallel Bond strengths). If the stress in the bond obtains the strength value in normal or tangential direction, the bond will break in the next timestep, and the elements will move only according to the Hertz-Mindlin contact model. The maximum normal $\left(\sigma_{\max }\right)$ and tangential bond stresses $\left(\tau_{\max }\right)$ can be determined using Eq. 11 and Eq. 12:

$$
\begin{gathered}
\sigma_{\text {max }}=\frac{-\Delta F^{n}}{A}+\frac{2 \cdot \Delta M^{s}}{J_{B}} \cdot R_{B}, \\
\tau_{\text {max }}=\frac{-\Delta F^{s}}{A}+\frac{\Delta M^{n}}{J_{B}} \cdot R_{B} .
\end{gathered}
$$




\subsection{Discrete element simulations of cone penetration test.}

To analyse the effect of the contact properties on simulation results, a lot of numerical cone penetration simulations were performed. First, the initial geometry of the soil was created by filling up a cylinder with diameter of $\varnothing 135,4 \mathrm{~mm}$ and height of $130 \mathrm{~mm}$ with spherical elements (Fig. 2/a). The size of the model was chosen according to our earlier research [16] where it is proved, that the boundary of the model is far enough from the cone penetrometer, thus it has negligible effect on simulation results. The particles were created using the Simple Sequential Inhibition (SSI) technique [17], which places elements with random diameter to random locations. The contact properties of the Hertz-Mindlin model for soil particles are summarized in Table 1. After the creation of the elements, the particles fell down to the bottom of the cylinder because of Earth gravity. Finally, when the whole system obtained the equilibrium state (the element's maximum velocity got smaller than 1e-2 mm/s), the Parallel Bonds were formed between the particles, then the geometry of the penetrometer cone (shown in Fig. 2/b) was imported into the program using an .stl file. The properties of the soil's Parallel Bond contact model and of the wall elements (as penetrometer cone) can be also seen in Table 1. Note, that some contact parameters of the soil were determined according to the process which is published in our earlier research [18], the remaining properties were chosen for sensitivity tests. These are presented in Table 1 as grey background, and the ranges where the effect of these contact properties were investigated, were also shown in the table. The properties of the penetrometer cone were chosen as general steel material. Additionally, the initial geometry of the system can be seen in Fig. 2/a.

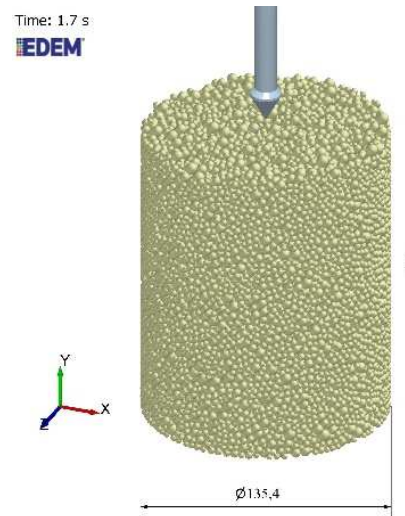

a)

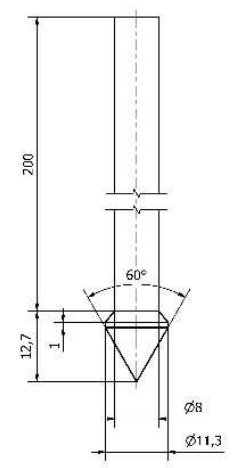

b)

Figure 2. The initial geometry of the soil (a) and the dimension of the used penetration bar (b). 
In the next step, the geometry of the penetrometer cone was pressed into the soil model with vertical speed of $20 \mathrm{~mm} / \mathrm{s}$, which is typical in cone penetration in-situ tests. During the simulations, the force acting on the penetrometer cone (as soil resistance) was calculated and was saved in each $0,05^{\text {th }}$ calculation time. This process was repeated in all discrete element simulations where the timestep was set to the value of $5 \mathrm{e}-6 \mathrm{~s}$.

Table 1. The settings of the discrete element cone penetration tests

\begin{tabular}{|c|c|}
\hline Parameter & Value \\
\hline \multicolumn{2}{|l|}{ Geometrical properties } \\
\hline Particle radius distribution $(\mathrm{mm})$ & $1,33 \ldots 3$ \\
\hline Contact radius $(\mathrm{mm})$ & $1,6 \ldots 3,6$ \\
\hline $\begin{array}{l}\text { Initial porosity (before the penetration bar } \\
\text { pressed into the soil) }(-)\end{array}$ & 0,425 \\
\hline \multicolumn{2}{|c|}{$\begin{array}{c}\text { Properties of the Hertz-Mindlin with bonding contact model between } \\
\text { the soil elements }\end{array}$} \\
\hline Density $\left(\mathrm{kg} / \mathrm{m}^{3}\right)$ & $1,6 \mathrm{e}+03 \ldots 2,0 \mathrm{e}+03$ \\
\hline Shear modulus $(\mathrm{Pa})$ & $1,44 \mathrm{e}+06 \ldots 1,44 \mathrm{e}+08$ \\
\hline Poisson ratio $(-)$ & $0,2 \ldots 0,3$ \\
\hline $\begin{array}{l}\text { Coefficient of restitution between the soil } \\
\text { particles (-) }\end{array}$ & 0,5 \\
\hline $\begin{array}{l}\text { Coefficient of restitution between the soil } \\
\text { particles and walls (-) }\end{array}$ & 0,5 \\
\hline Friction coefficient between ball and ball (-) & 0,4 \\
\hline Friction coefficient between ball and walls (-) & 0,6 \\
\hline Bond radius $(\mathrm{mm})$ & $0,5 \ldots 5,0$ \\
\hline Bond normal stiffness $(\mathrm{Pa} / \mathrm{m})$ & \multirow{2}{*}{$9,5 \mathrm{e}+06 \ldots 4,75 \mathrm{e}+07$} \\
\hline Bond shear stiffness $(\mathrm{Pa} / \mathrm{m})$ & \\
\hline Bond normal strength $(\mathrm{Pa})$ & $3,131 \mathrm{e}+4$ \\
\hline Bond shear strength $(\mathrm{Pa})$ & $4,428 \mathrm{e}+4$ \\
\hline \multicolumn{2}{|c|}{$\begin{array}{c}\text { Properties of the Hertz-Mindlin contact model between the } \\
\text { penetrometer (wall) elements }\end{array}$} \\
\hline Density $\left(\mathrm{kg} / \mathrm{m}^{3}\right)$ & $7,8 \mathrm{e}+03$ \\
\hline Shear modulus $(\mathrm{Pa})$ & $7,692 \mathrm{e}+10$ \\
\hline Poisson ratio (-) & 0,3 \\
\hline Coefficient of restitution between walls (-) & 0,5 \\
\hline Friction coefficient between wall and wall (-) & 0,1 \\
\hline
\end{tabular}




\section{Results and Discussion}

In this section, the results of the sensitivity test of numerical discrete element penetration simulations are shown. First all simulations were evaluated qualitatively which means that we analysed the broken Parallel Bonds, the compression force and the velocity of the particles before evaluating the vertical forces that acts on the penetration cone. Fig. 3 shows typical results of the simulations, the broken bonds are presented as blue lines in Fig. 3/a. It can be asserted, that they break near the penetration cone which can be acceptable. In the part b) and $c$ ) of the figure, the compression force of the particles and their velocities are shown, respectively. It can be clearly seen that the highest forces arise in front of the cone. Similar to that can be said in case of the element's velocity, however high velocities can be experienced near the penetration bar as well. This is because of the friction between the penetrometer and the soil particles, and is similar to the results in Tanaka et al [9]. According to these, we concluded that the simulation results are in accordance with our expectations and the results of other researches, thus the calculations provided good results qualitatively.

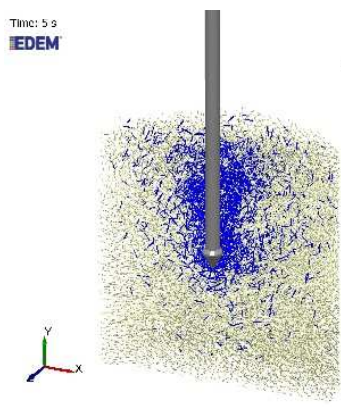

a)

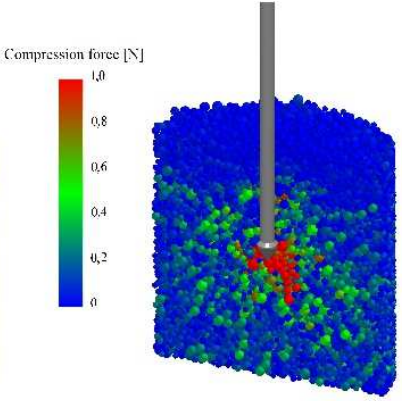

b)

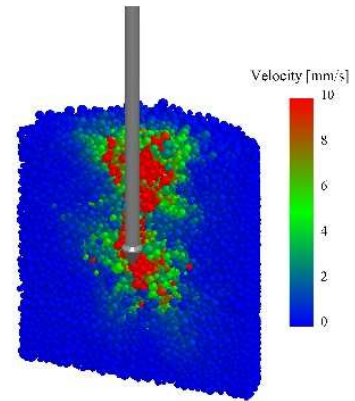

c)

Figure 3. The broken bonds (a), the compression force between the elements (b) and the particle's velocity (c) at penetration depth of $64 \mathrm{~mm}$.

In the next step, we investigated the results quantitatively as well, the penetration resistance-penetration depth curves were compared in case of different contact properties values. First, the effect of the particle's density and Poisson-ratio on soil resistance to penetration were analysed. Fig. 4 shows the results in case of different density values. It can be asserted, that this contact property does not have significant effect on penetration resistance, the curves are almost the same. Similar to that can be concluded in case of different Poisson-ratio (Fig. 5), because there are small differences in the penetration resistance-depth curves. 


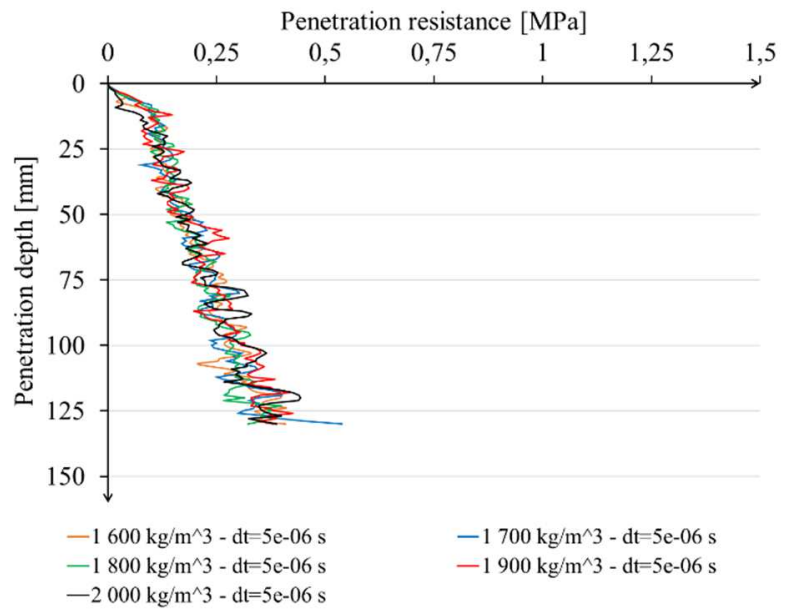

Figure 4. The effect of the particle's density on penetration resistance.

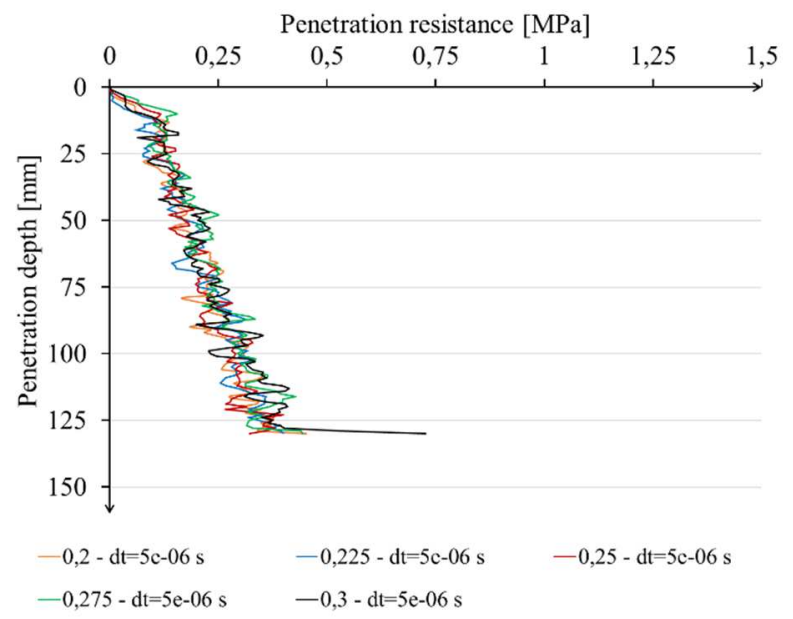

Figure 5. The effect of the particle's Poisson-ratio on penetration resistance.

However, this is not the case in the simulations with different particle's shear modulus. Fig. 6 shows that the penetration resistance is increasing when this contact property is increased as well, but this tendency is stopped in case of shear modulus of $4,32 \mathrm{e}+07 \mathrm{~Pa}$. If higher than this value is set up in the simulations, this parameter has negligible effect on soil's resistance to penetration. 


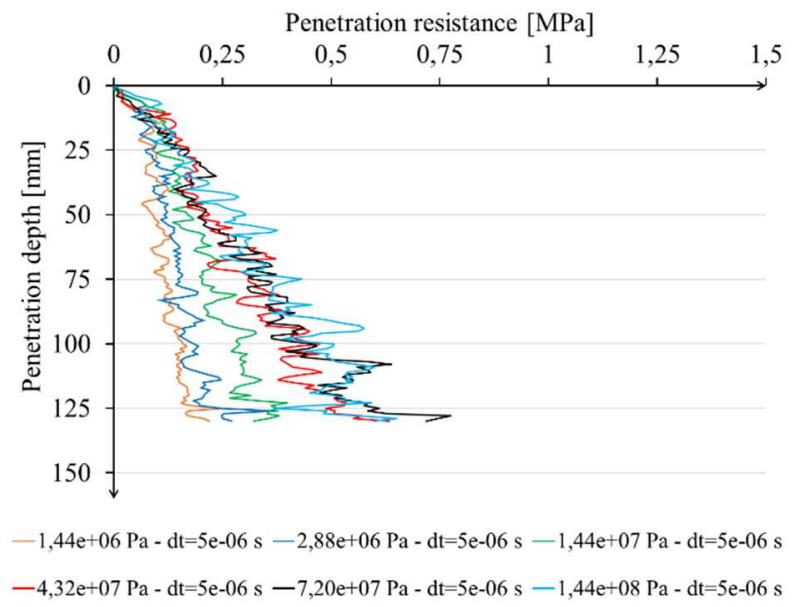

Figure 6. The effect of the particle's shear modulus on penetration resistance.

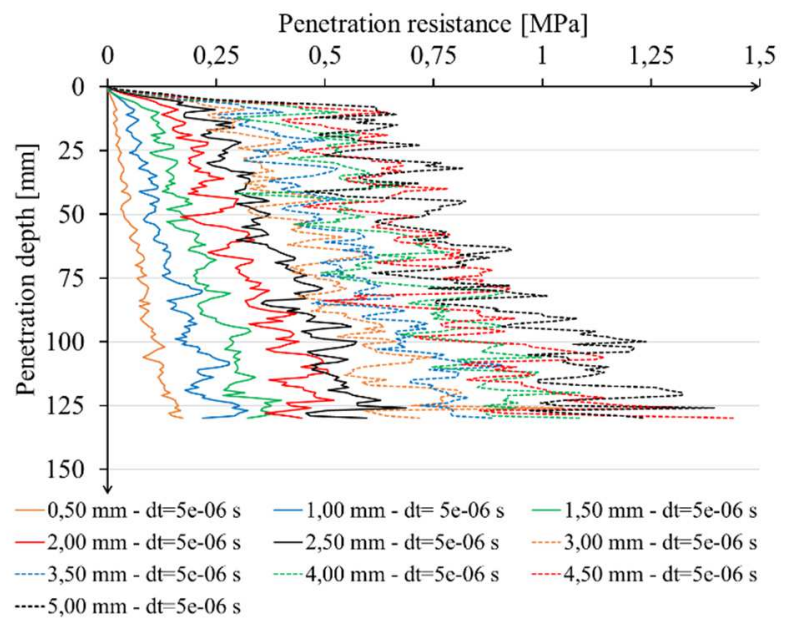

Figure 7. The effect of the Parallel Bond radius on penetration resistance.

Parallel Bond radius also has large effect on simulation results. According to Fig. 7, the higher the value of this parameter is, the force acting on the penetration cone, thus the penetration resistance of the soil model will be higher as well. This conclusion stands in the whole range (namely the value from $0,5 \mathrm{~mm}$ to $5,0 \mathrm{~mm}$ ), where this contact property was investigated. 
In Fig. 8, the results can be seen in case of different Parallel Bond stiffness. It can be asserted, that the effect of this parameter is very similar to the experienced one in case of particle's shear modulus. Namely, if the bond stiffness is increasing from $9,5 \mathrm{e}+06 \mathrm{~Pa} / \mathrm{m}$ to $2,85 \mathrm{e}+07 \mathrm{~Pa} / \mathrm{m}$, the model's resistance to penetration will increase as well. But in case of the highest Parallel Bond stiffness values, the penetration resistance-depth curves are similar to each other, thus this parameter has no significant effect on simulation results in this range of value.

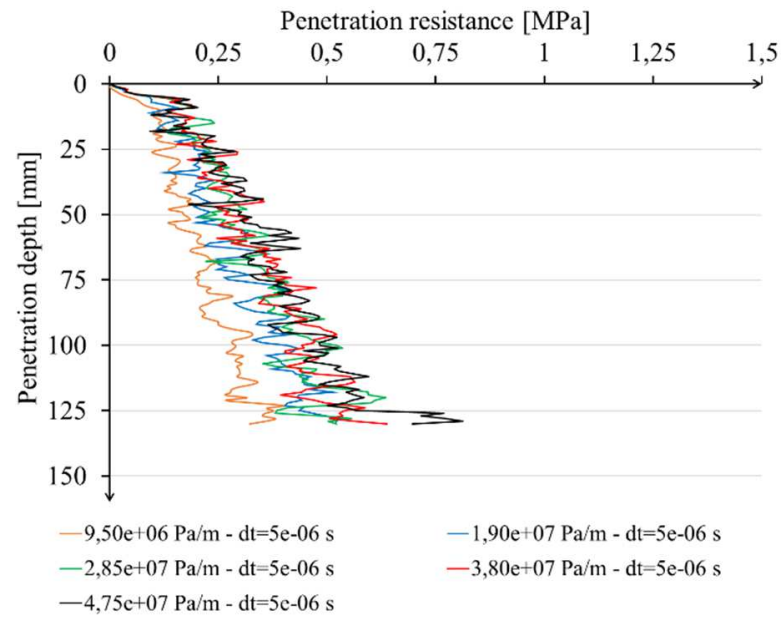

Figure 8. The effect of the Parallel Bond stiffness on penetration resistance.

\section{Conclusion}

In this paper, the discrete element method was adopted to model the cone penetration in-situ measurements. We used the Hertz-Mindlin with bonding contact model to simulate cohesive soil and our aim was to investigate the effect of the contact properties on simulation results, namely on penetration resistancepenetration depth curve. We concluded that the Parallel Bond radius, stiffness and the elements' shear modulus affect the results, thus they play important role in calibration of the contact properties to the result of in-situ penetration test. On the other hand, the particle's density and Poisson-ratio have negligible effect on the penetration resistance-depth curve in the investigated range, therefore it is not necessary to take these into account in the calibration process. 


\section{Acknowledgement}

The research reported in this paper was supported by the Higher Education Excellence Program of the Ministry of Human Capacities in the frame of Artificial intelligence research area of Budapest University of Technology and Economics (BME FIKP-MI).

\section{References}

[1] L. Laib (Ed.), Terepen mozgó jármüvek (Moving off-road vehicles). Szaktudás Kiadó Ház, Budapest, 2002, in Hungarian.

[2] E. McKyes, Soil Cutting and Tillage, The University of Michigan, Michigan, 1985.

[3] M. Kuczmann, Overview of the Finite Element Method. Acta Technica Jaurinensis 8 (2015) pp. 347-383.

doi: https://doi.org/10.14513/actatechjaur.v8.n4.393

[4] P. Horváth, J. Égert, Dynamic Analysis of a One-cylinder Engine Crankshaft. Acta Technica Jaurinensis 8 (2015) pp. 280-295.

doi: https://doi.org/10.14513/actatechjaur.v8.n4.379

[5] P. T. Zwierczyk, K. Váradi, Frictional contact FE analysis in a railway wheelrail contact. Periodica Polytechnica Mechanical Engineering 58 (2014), pp. 93-99.1 doi: https://doi.org/10.3311/PPme.7229

[6] W. A. Foster Jr., C. E. Johnson, R. C. Chiroux, T. R. Way, Finite element simulation of cone penetration. Applied Mathematics and Computation 162 (2005), pp. 735-749.

doi: https://doi.org/10.1016/j.amc.2004.01.012

[7] M. Z. Tekeste, R. L. Raper, E. W. Tollner, T. R. Way, Finite element analysis of cone penetration in soil for prediction of hardpan location. Transactions of the ASABE 50 (2007), pp. 23-31.

[8] P. A. Cundall, O. D. L. Strack, A discrete numerical model for granular assemblies. Géotechnique 29 (1979), pp. 47-65.

doi: https://doi.org/10.1680/geot.1979.29.1.47 
[9] H. Tanaka, M. Momozu, A. Oida, M. Yamazaki, Simulation of soil deformation and resistance at bar penetration by the Distinct Element Method. Journal of Terramechanics 37 (2000), pp. 41-56. doi: https://doi.org/10.1016/S0022-4898(99)00013-0

[10] J. Butlanska, M. Arroyo, A. Gens, Homogeneity and Symmetry in DEM Models of Cone Penetration. AIP Conference Proceedings 1145 (2009), pp. 425-428.

doi: https://doi.org/10.1063/1.3179952

[11] J. Butlanska, M. Arroyo, A. Gens, C. O’Sullivan, Multi-scale analysis of cone penetration test (CPT) in a virtual calibration chamber. Canadian Geotechnical Journal 51 (2013), pp. 51-66. doi: https://doi.org/10.1139/cgj-2012-0476

[12] H. Hertz, On the contact of elastic solids. J. reine und angewandte Mathematik 92 (1882), pp. 156-171.

[13] R. D. Mindlin, Compliance of elastic bodies in contact. Journal of Applied Mechanics 16 (1949), pp. 259-268.

[14] R. D. Mindlin, H. Deresiewicz, Elastic spheres in contact under varying oblique forces. ASME (1953) pp. 327-344.

[15] D. O. Potyondy, P. A. Cundall, A bonded-particle model for rock. International Journal of Rock Mechanics and Mining Sciences, Rock Mechanics Results from the Underground Research Laboratory, Canada 41 (2004), pp. 1329-1364.

doi: https://doi.org/10.1016/j.ijrmms.2004.09.011

[16] K. Kotrocz, A. M. Mouazen, Gy. Kerényi,. Numerical simulation of soil cone penetrometer interaction using discrete element method. Computers and Electronics in Agriculture 125 (2016):(C) pp. 63-73.

doi: https://doi.org/10.1016/j.compag.2016.04.023

[17] J. W. Evans, Random and cooperative sequential adsorption. Reviews of Modern Physics 65 (1993), pp. 1281-1329.

doi: https://doi.org/10.1103/RevModPhys.65.1281 
[18] K. Kotrocz, Gy. Kerényi, Numerical Discrete Element Simulation Of Soil Direct Shear Test, 31st Conference on Modelling and Simulation, ECMS 2017, Budapest, Hungary, pp. 510-515. Edited by: Zita Zoltay Paprika, Péter Horák, Kata Váradi, Péter Tamás Zwierczyk, Ágnes Vidovics-Dancs, János Péter Rádics.

doi: https://doi.org/10.7148/2017-0510 